\title{
A CHEMICAL AND HISTOCHEMICAL STUDY OF ALIESTERASE IN THE ADRENAL GLAND OF THE DEVELOPING MOUSE ${ }^{1}$
}

\author{
JOHN M. ALLEN \\ Department of Zoology, University of Michigan, \\ Ann Arbor, Michigan \\ NINE FIGURES
}

The activity of histochemically determined aliesterase in the adrenal cortex of the adult mouse has been shown to be responsive to environmental modification (Allen, '57). In the zona glomerulosa the activity of this enzyme was increased under conditions of sodium deprivation and was decreased by sodium flooding. Aliesterase in the zona glomerulosa appeared to be independent of the influence of pituitary adrenocorticotrophic hormone (ACTH). On the other hand, aliesterase activity in the zona fasciculata was found to be under the control of ACTH and did not respond to alteration of sodium intake. In spite of the fact that the physiological role of aliesterase in the adrenal cortex of the mouse is unknown these results suggested that histochemical determinations of the activity of this enzyme might be good indices of the functional status of the tissue.

Considerable interest attaches to the establishment of the time at which the adrenal cortex begins to function in development. Studies of this problem have been made by utilizing histochemical tests for lipids (Dawson, '53; Josimorich et al., '54; Lever, '55; Moog et al., '54; van Dorp and Deane, '50). Interpretation of functional status in terms of lipid content, however, appears difficult. A better index might be that given

\footnotetext{
${ }^{1}$ This research has been supported by a grant for the National Cancer Institute of the U. S. Public Health Service (C-2751).
} 
by determinations of enzyme activity in the adrenal cortex during development. No extensive studies of this nature have been carried out but incidental observations are reported (Nicander, '54; Rossi et al., '57). The behavior of chemically and histochemically determined aliesterase in the adrenal cortex of the developing mouse forms the subject of this paper.

\section{METHODS}

All work was carried out on adrenal glands from BALB/c Jax mice. Embryos were dated from 2400 hours of the day on which the copulation plug was observed. Newborn and older animals were dated in reference to time of birth as determined by animal inspection at 0800 hours and 2000 hours. Aliesterase was determined histochemically as described by Pearse ('53) with alpha-naphthyl acetate as substrate and Diazo Garnet GBC (duPont Company) as coupling agent. Adrenals for study were fixed in $10 \%$ formalin buffered to $\mathrm{pH} 7.0$ and made isotonic with a phosphate buffer system. Fixation was carried out for 12 hours at $4^{\circ} \mathrm{C}$. Tissues were sectioned at $20 \mu$ on a freezing microtome and dry-mounted on slides. Prior to immersion in the histochemical substrate, sections were extracted for one minute in acetone at room temperature to remove neutral fats. This procedure did not alter the intensity or the distribution of dye deposition in sections. These sections were incubated in the substrate solution with constant agitation for 10 minutes at $20^{\circ} \mathrm{C}$. Sections treated with water at $90^{\circ} \mathrm{C}$ for 10 minutes served as no enzyme controls. Histochemical determinations were made (a) on a series of glands composed of a minimum of 4 animals per group taken at 24 -hour intervals from 16 days after insemination to 30 days after birth and (b) on a series of glands composed of a minimum of 8 animals per group and equally divided between the sexes which represented activity at 0 , $7,14,21$, and 28 days after birth. Control sections were derived from males 90 days old.

Quantitative determinations of aliesterase activity were carried out on homogenates of fresh adrenal tissue according 
to the procedure of Gomori ('52), with alpha-naphthyl acetate as substrate and Fast Red Salt ITR (General Dyestuff Company) as coupling agent. The substrate solution for quantitative determinations contained $10^{-5} \mathrm{M}$ eserine sulfate to block the activity of cholinesterases known to be present in the medullary tissue of these glands (Allen, unpublished data). This concentration of eserine sulfate had no effect on the amount or distribution of dye deposition in the cortex when checked in histochemical preparations. Incubation was carried out at $37^{\circ} \mathrm{C}$ for one hour. Color developed was measured in a Coleman Model 6A spectrophotometer at $540 \mathrm{~m} \mu$. Total nitrogen in the samples used for quantitative analysis was determined by a direct Nesslerization procedure (Levy, '36). Color developed was measured in a Coleman Model 6A spectrophotometer at $460 \mathrm{~m} \mu$. Data were analyzed using the Kendall Sum test or the Mann-Whitney " $U$ " test.

The morphological development of the adrenal gland of the mouse has been described by Waring ('35).

\section{RESULTS}

\section{Histochemical studies}

Sixteen days after insemination to birth (fig. 2). During this phase of development all adrenal cortical cells were characterized by the presence of low levels of esterase activity. The enzyme was present in the cytoplasm of cortical epithelial cells. Nuclei and connective tissues were negative. A slight increase in activity of the enzyme in cortical epithelial cells was noted by the time of birth. Cells of the zona glomerulosa and the zona fasciculata showed comparable levels of activity. In some sections, epithelial cells of the interlocking zone ( $\mathrm{X}$ zone) showed slightly more activity than other cortical cells. Adrenal glands from males and females exhibited equivalent patterns of activity.

Birth to 7 days after birth (fig. 3). During the first week after birth striking increases in the activity of aliesterase were noted in the interlocking zone. Enzyme activity in the 
zona fasciculata and the zona glomerulosa increased only slightly during this perid of time. Activity in these zones was much less than that observed in adult control animals. Some sections showed slight elevation of activity in the zona glomerulosa above that noted in the zona fasciculata but in the majority of cases activity levels in these two zones were equivalent. No sex difference in the activity of aliesterase was observed in any of the cortical zones.

Seven to 14 days after birth (fig. 4). Aliesterase activity in the interlocking zone remained comparable to that observed at 7 days after birth. However, increases in the activity of aliesterase were observed in the zona fasciculata. By 14 days of age the activity of the enzyme in this zone had reached levels equivalent to those seen in the zona fasciculata of the adult control animals. Further slight increases in the activity of the enzyme in the zona glomerulosa were observed but levels of activity were only slightly greater than those noted in animals at 7 days of age and were clearly less than those prevailing in adult control animals. No sexual dimorphism in the activity of aliesterase was observed in any cortical zone.

Fourteen to 21 days after birth (fig. 5). During this period aliesterase activity in the interlocking zone decreased as compared with its activity at 7 and 14 days of age. Activity of the enzyme in the zona fasciculata and the zona glomerulosa remained comparable to that noted in animals 14 davs old. Isolated sections suggested increased aliesterase activity in the zona glomerulosa by 21 days after birth but in no case was the activity equal to that seen in sections from adult control animals. No sex difference in the activity of aliesterase was observed in any cortical zone.

Twenty-one to 28 days after birth (figs. 6 and 7 ). Aliesterase activity in the interlocking zone remained low and showed levels comparable to those prevailing in animals 21 days old. In the zona fasciculata of male animals the activity of aliesterase was comparable to that noted at 14 and 21 days after birth and was equivalent to the activity seen in control sections. The female of 28 days of age, however, showed 
a slight increase in the activity of aliesterase in the innermost region of the zona fasciculata. Other regions of the zona fasciculata showed levels of activity equivalent to those seen in control males. This slight increase in the activity of the enzyme in the inner regions of the zona fasciculata of the 28-day-old female was doubtless an early indication of the marked sexual dimorphism which became evident in the 90day-old virgin female (see below) in reference to aliesterase activity. By 28 days of age the levels of aliesterase activity found in the zona glomerulosa were greater than those noted at previous stages and were equivalent to those seen in this zone in 90-day-old control animals.

Status of adrenal cortical aliesterase in the 90-day old animal (figs. 8 and 9). No further changes in the activity or in the distribution of aliesterase were observed in the male.

In the 90-day-old virgin female, however, a striking increase in the activity of aliesterase in the zona fasciculata was apparent. This increase in activity involved primarily the inner regions of the zona fasciculata but the entire zone showed elevated activity as compared with the 90-day-old male. Aliesterase activity in the zona glomerulosa was comparable to that observed in the male. Activity of the enzyme in the interlocking zone was not essentially changed from that observed at 30 days of age. Diffusion of dye due to the intense activity present in the contiguous cortical zone made comparison of activity levels inaccurate.

\section{Quantitative Studies}

Quantitative studies of aliesterase activity in the adrenal gland of the developing mouse (table 1 and fig. 1) supported the trends observed in histochemical studies. Inspection of figure 1 indicates that enzyme activity in embryonic stages was low and consistent. An increase in the activity of aliesterase took place during the first 13 days after birth. No further increase in aliesterase activity occurred subsequent to the 17 th day after birth. The $95 \%$ confidence limits (pooled) for the time period from 16-30 days after birth indicated that 
200

JOHN M. ALLEN

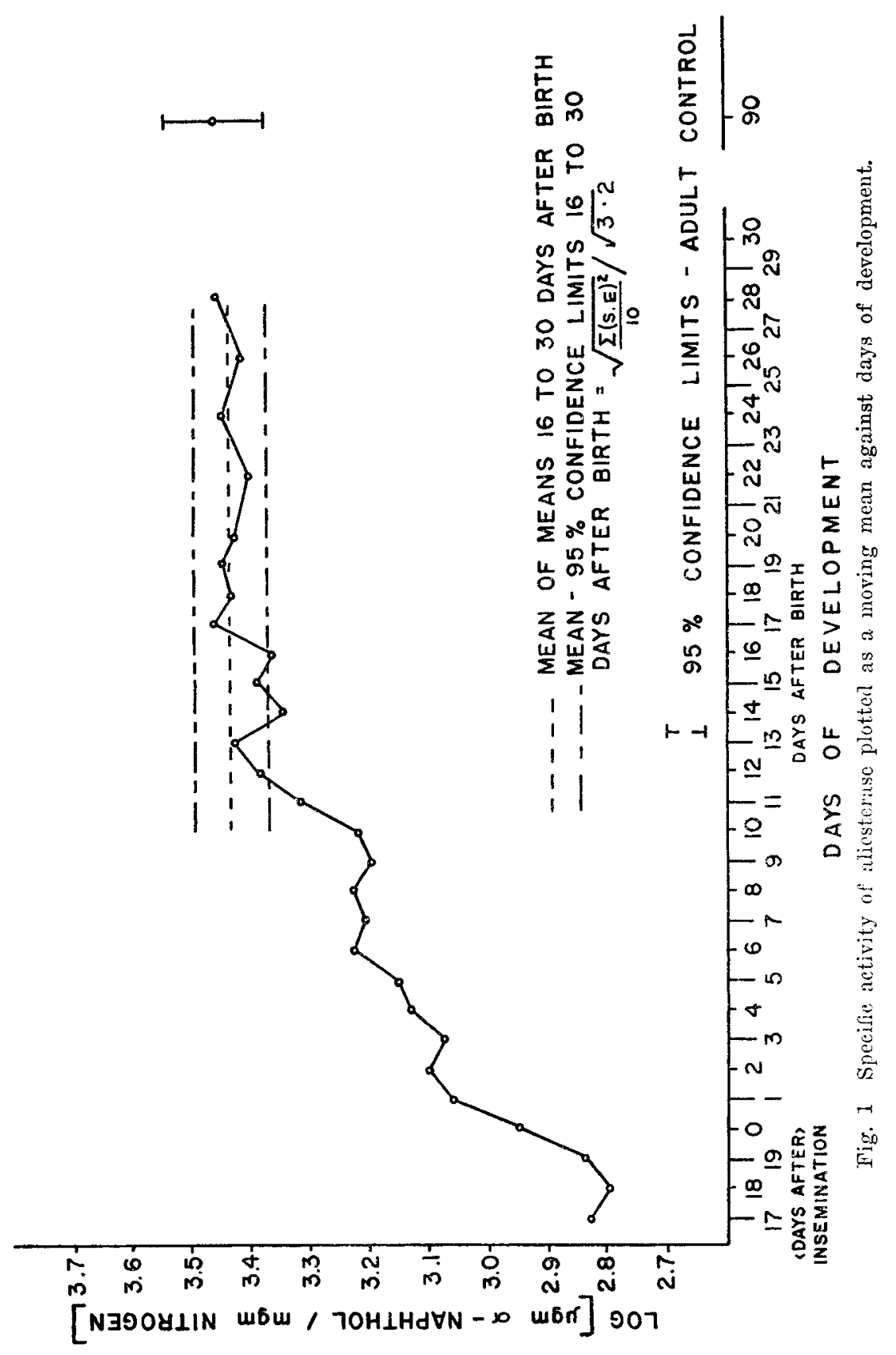


adult control levels of activity were reached between 11 and 16 days of age. The Mann-Whitney " $U$ "' test indicated that all points from 11 days to 30 days after birth were comparable with the adult control group $(\mathrm{P}>0.05)$. This same test indicated that all samples prior to 11 days after birth were significantly less active than the adult control group $(\mathrm{P}<$ 0.05). The Kendall Sum test suggested that no quantitative difference in aliesterase activity existed between adrenal glands from males and females at any age period up to 30 days after birth $(\mathrm{P}>0.05)$. Therefore data for males and females were pooled.

TABLE 1

Quantitative estimate of aliesterase activity of the adrenal gland in the developing mouse

\begin{tabular}{|c|c|c|}
\hline $\begin{array}{c}\text { DAYS OF } \\
\text { DEVILOPMENT }\end{array}$ & $\begin{array}{c}\text { NUMBER OF } \\
\text { ANIMALS }\end{array}$ & $\begin{array}{c}\text { MEAN LOG SPECIFIC } \\
\text { ACTIVITY }\end{array}$ \\
\hline 16 days after insemination & $9(3)^{1}$ & $2.846 \pm 0.058$ \\
\hline 17 days after insemination & $14(7)^{1}$ & $2.865 \pm 0.033$ \\
\hline 18 days after inscmination & $13(7)^{1}$ & $2.763 \pm 0.110$ \\
\hline 19 days after insemination & 6 & $2.770 \pm 0.048$ \\
\hline Newborn & 12 & $2.976 \pm 0.097$ \\
\hline 1 day after birth & 9 & $3.097 \pm 0.037$ \\
\hline 2 days after birth & 12 & $3.113 \pm 0.048$ \\
\hline 3 days after birth & 9 & $3.096 \pm 0.048$ \\
\hline 4 days after birth & 11 & $2.993 \pm 0.041$ \\
\hline 5 days after birth & 15 & $3.316 \pm 0.001$ \\
\hline 6 days after birth & 13 & $3.127 \pm 0.057$ \\
\hline 7 days after birth & 13 & $3.250 \pm 0.036$ \\
\hline 8 days after birth & 8 & $3.262 \pm 0.074$ \\
\hline 9 days after birth & 3 & $3.176 \pm 0.161$ \\
\hline 10 days after birth & 13 & $3.159 \pm 0.014$ \\
\hline 11 days after birth & 9 & $3.315 \pm 0.105$ \\
\hline 12 days after birth & 10 & $3.496 \pm 0.046$ \\
\hline 13 days after birth & 11 & $3.371 \pm 0.058$ \\
\hline 14 days after birth & 15 & $3.424 \pm 0.047$ \\
\hline 35 days after birth & 15 & $3.260 \pm 0.036$ \\
\hline 16 days after birth & 7 & $3.474 \pm 0.038$ \\
\hline 17 days after birth & 14 & $3.389 \pm 0.030$ \\
\hline 18 days after birth & 14 & $3.532 \pm 0.045$ \\
\hline 19 days after birth & 17 & $3.410 \pm 0.063$ \\
\hline 20 days after birth & 8 & $3.402 \pm 0.069$ \\
\hline 22 days after birth & 12 & $3.477 \pm 0.035$ \\
\hline 24 days after birth & 8 & $3.360 \pm 0.080$ \\
\hline 26 days after birth & 12 & $3.512 \pm 0.033$ \\
\hline 28 days after birth & 13 & $3.401 \pm 0.031$ \\
\hline 30 days after birth & 12 & $3.464 \pm 0.035$ \\
\hline Adult ${ }^{3}$ & 18 & $3.474 \pm 0.038$ \\
\hline
\end{tabular}

1 Pooled sample; effective " $N$ "' in parentheses.

Micrograms of alpha-naphthol liberated in one hour at $37^{\circ} \mathrm{C}$ per milligram of total nitrogen in the sample under analysis, followed by standard error.

90-day-old intact males. 
DISCUSSION

If, as previous work suggests (Allen, '57), aliesterase activity levels form an accurate index of adrenal cortical function, certain deductions are permissible from the above findings in reference to the time at which the adrenal cortex of the developing mouse assumes functional activity comparable with that of the adult male. Histochemical studies indicated that the development of adrenal cortical aliesterase activity falls into four more or less distinct phases: (1) Embryonic period, characterized by low and relatively constant aliesterase activity in all cortical cells, (2) birth to 7 days after birth, characterized by development of high activity in the interlocking zone with only slight change in the activity of the permanent cortex, (3) 7 to 14 days after birth, characterized by the emergence of adult levels of aliesterase activity in the zona fasciculata, and (4) 14 to 28 days after birth, characterized by a marked lessening of aliesterase activity in the interlocking zone and the rather gradual development of adult levels of enzyme activity in the zona glomerulosa. Quantitative determinations of aliesterase activity suggested that levels of activity comparable to those prevailing in the 90-day-old male were reached between 11 and 16 days of age. This latter estimate is perforce crude since it includes activity derived from all cortical zones. The major component of activity measured, however, is probably derived from the zona fasciculata for this zone comprises the largest part of the cortex during this phase of development. In terms of the zones of the permanent cortex it seems, on the basis of the criteria of aliesterase activity, that the zona fasciculata reaches secretory levels which are equivalent to those found in adult males by the 14th day after birth. Secretory activity in the zona glomerulosa is delayed and does not reach adult levels until about the 28th day after birth.

The suggestion that the zona fasciculata reaches full secretory status by the 14th day after birth is in agreement with predictions based on other eriteria. Moog ('54), using several cytochemical tests for lipids, concluded that the zona fasciculata of the mouse adrenal cortex markedly increases its secre- 
tory activity during the period 10 to 16 days after birth. Using duodenal alkaline phosphatase levels as an indicator of corticoid production by the mouse adrenal gland this same author (Moog, '53) concluded that elevated hormone production commenced at the 15th day after birth.

The conclusion that adult levels of hormone production by the zona glomerulosa may be delayed until the 4 th week following birth is at variance with predictions made on the basis of stainability with lipid reagents (Moog, '54). Decreases in content of Sudan black-stainable material as well as decreases in the intensity of the Ashbel-Seligman reaction suggested to Moog that this zone may increase its functional activity about the same time as does the zona fasciculata (between 10 and 15 days of age). Resolution of this problem at the present writing does not seem possible.

The significance of high aliesterase activity in the interlocking zone between 7 and 14 days of age and the subsequent decrease in the activity of the enzyme is difficult to evaluate. The appreciable content of Sudan black-stainable and AshbelSeligman reactive material in this zone between birth and 14 days of age and its loss after 16 days of age is interesting (Moog, '54). Aliesterase activity follows a similar course and it is possible that the enzyme may be implicated in the metabolism of these lipids in the interlocking zone (Ammon and Jaarma, '50). Elevated activity of aliesterase in the interlocking zone of the mouse adrenal during the first 14 days after birth suggests that this region may play an important functional role during this period. The nature of this function is largely unknown but the $\mathrm{X}$-zone of the mouse has been implicated in androgen formation (Howard, '39). Formation of glucocorticoids (Jones, '49) and mineralocorticoids (Howard, '40) by this tissue appears doubtful.

A marked sexual difference in morphological development of the adrenal cortex of the mouse exists (Waring, '35). Studies of alkaline phosphatase in the adrenal cortex of the mouse (Allen and Slater, '56) have demonstrated a sexual difference at the enzymatic level. The present work extends the biochemical sexual dimorphism of the adrenal cortex of 
the mouse to include aliesterase. Preliminary observations (Allen, unpublished data) suggest that the elevated levels of aliesterase found in the adrenal cortex of the 90-day-old virgin female may be under the control of ovarian hormones. This sexual dimorphism makes itself evident at 4 weeks of age. Failure of quantitative determinations to show a similar sex difference in adrenals from animals 28 days of age is probably due to dilution of the heightened aliesterase activity in the inner zone of the cortex by less reactive medullary and cortical tissues. The relationship between this high aliesterase activity in the adrenal cortex of the female and adrenocortical function is unknown.

\section{SUMMARY}

Aliesterase activity in the adrenal gland of the developing mouse has been investigated from 16 days after insemination to 30 days after birth using chemical and histochemical methods.

Histochemical studies indicated that the development of adrenal cortical aliesterase activity falls into 4 phases: (1) Embryonic period, characterized by low aliesterase activity in all cortical cells, (2) birth to 7 days after birth, characterized by development of high activity in the interlocking zone with slight change in the activity of the permanent cortex, (3) 7 to 14 days after birth, characterized by the emergence of adult levels of aliesterase activity in the zona fasciculata, and (4) 14 to 28 days after birth, characterized by marked lessening of aliesterase activity in the interlocking zone and the development of adult levels of enzyme activity in the zona glomerulosa.

Quantitative determinations of aliesterase activity confirmed the histochemical observations and suggested that adult levels of aliesterase activity were reached between 11 and 16 days after birth.

These results were interpreted in terms of adrenal cortical function and suggested that the zona fasciculata of the adrenal cortex of the mouse reaches full functional activity by 14 days of age while attainment of adult functional levels in the zona 
glomerulosa is delayed until the end of the 4 th week after birth.

\section{LITERATURE CITED}

Alles, J. 1957 A chemical and histochemical study of aliesterase in mouse adrenal cortex under hormonal influences and altered sodium intake. Endocrinology, 61: 368-374.

Allen, J., AND J. Slater 1956 Influence of hormones upon the distribution of alkaline phosphatase in mouse adrenal cortex. J. Histochem. Cytochem., 4: 110-117.

Ammon, R., AND M. JAARMA 1950 Enzymes hydrolyzing fats and esters. In: The Enzymes I, J. Sumner and K. Myrbäck, editors. Academic Press, Inc., New York. Chap. IX, pp. 390-442.

Dawson, A. 1953 Histochemical evidence of early differentiation of the suprarenal gland of the chick. J. Morph., 92: 445-453.

Gomori, G. 1952 Human esterases. J. Lab. Clin. Med., 42: 445-453.

How ARD, E. 1939 Effects of castration on the seminal vesicles as influenced by age, considered in relation to the degree of development of the adrenal X-zone. Am. J. Anat., 65: 105-149.

1940 Regarding the effects of desoxycorticosterone and of testosterone on the adrenal X-zone. Anat. Rec., $77: 181-188$.

JoNes, I. 1949 The relationship of the mouse adrenal cortex to the pituitary. Endocrinology, 45: 514-536.

Josimovich, J., A. Ladman AND H. Drane 1954 Histophysiologie study of developing adrenal cortex of the rat during fetal and early postnatal stages. Endocrinology, 54:627-639.

Lever, J. 1955 Adrenocortical histogenesis in the rat embryo with observations on lipide and ascorbic acid distribution. J. Anat., 89: 293-300.

Levy, M. 1936 Studies on enzymatic histochemistry. XVII. A micro-Kjeldahl estimation. Compt. Rend. trav. Carlsberg, Ser. chim., 21: 101-110.

Moog, F. 1953 The functional differentiation of the small intestine. III. The influence of the pituitary-adrenal system on the differentiation of phosphatase in the duodenum of the suckling mouse. J. Exp. Zool., 124: $329-346$.

Moog, F., D. J. BennetT AND C. Dean 1954 Growth and eytochemistry of the adrenal gland of the mouse from birth to maturity. Anat. Rec., 120: $873-892$.

NICANDER, L. 1952 Histological and histochemical studies on the adrenal cortex of domestic and laboratory animals. Acta Anat., 14: Suppl. 16, 1-88.

Pearse, E. 1953 Histochemistry, Theoretical and Applied. Little, Brown and Company, Boston.

Rossi, F., G. Pescetto and E. Reale 1957 Enzymatic activities in human ontogenesis: First synoptic table of histochemical research. J. Histochem. Cytochem., $5: 221-235$.

VAN DORP, A., AND H. DEANE 1950 A morphological and cytochemical study of the postnatal development of the rat's adrenal cortex. Anat. Rec., 107: 265-281.

WARING, H. 1935 The development of the adrenal gland of the mouse. Quart. J. Micr. Sci., 78: 329-366. 


\section{PLATE 1}

\section{EXPLANATION OF FIGURES}

All photographs represent a magnification of $125 \times$. Plate and print exposure and processing are identical for all photographs except for figure 9. The print for figure 9 was developed for one-half the time used to produce prints for figures $2-8$.

2 Aliesterase activity in the adrenal of a newborn male mouse. Enzyme activity is evenly distributed in the cells of the cortex but a suggestion of increased activity may be noted in the interlocking zone.

3 Aliesterase activity in the adrenal of a 7-day-old female mouse. High aliesterase activity is present in the interlocking zone but activity in the zona fasciculata is only slightly elevated when compared to figure 2.

4 Aliesterase activity in the adrenal of a 14-day-old mouse. Aliesterase activity in the interlocking zone is comparable with that seen in figure 2 but the activity of the enzyme in the zona fasciculata is equal to that seen in the adult male control animal (fig. 8).

5 Aliesterase activity in the adrenal of a 21-day-old female mouse. Enzyme activity in the interlocking zone is depressed as compared to that seen at 7 and 14 days of age (figs. 3 and 4 ). Activity in the zona fasciculata shows 110 further change and activity in the zona glomerulosa is less than that seen in the adult male control animal (fig. 8).

6 Aliesterase activity in the adrenal of a 28-day-old female mouse. Enzyme activity in the zona glomerulosa is within the range observed in adult control animals (fig. 8). Aliesterase activity in the interlocking zone and the zona fasciculata is not changed from the condition noted at 21 days of age (fig. 5). A slight increase in the activity of aliesterase in the inner regions of the adrenal cortex is evident.

7 Aliesterase activity in the adrenal of a 28-day-old male mouse. The interlocking zone is no longer visible. The distribution and activity of aliesterase are comparable to that seen in the adult male control animal (fig. 8).

8 Aliesterase activity in the adrenal of a 90-day-old male mouse.

9 Aliesterase aetivity in the adrenal of a 90-day-old virgin female mouse in diestrus. Intense aliesterase activity is noted in the zona fasciculata. Diffusion of dye from the adjacent zona fasciculata makes difficult the evaluation of enzyme activity in the interlocking zone. Activity of aliesterase in the zona glonerulosa, although appearing to be less active than that seen in figure 8 , is actually equivalent. 

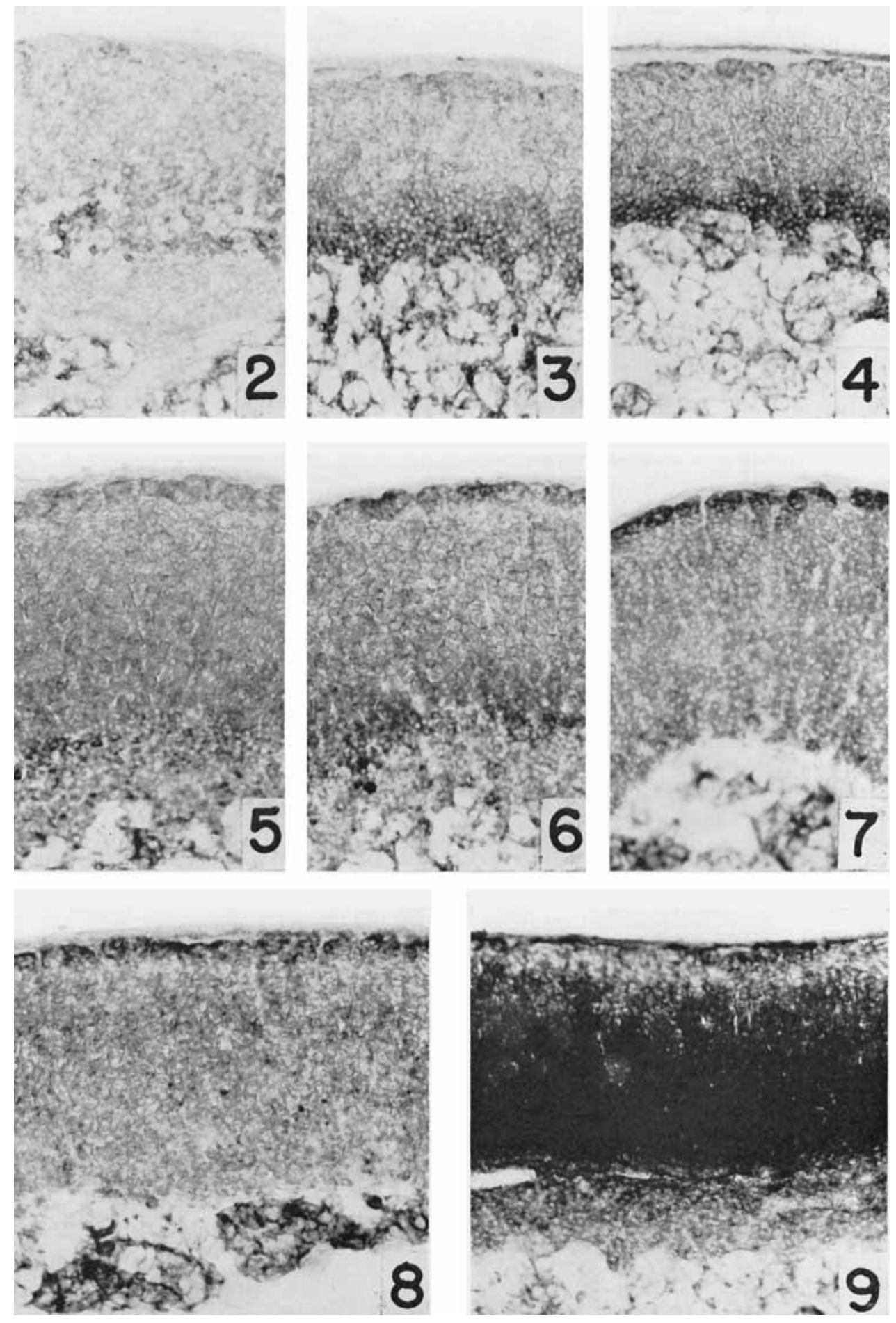